\title{
A Comparison of Immediate and Short-Term Defensive Responses to Phytophthora Species Infection in Both Susceptible and Resistant Walnut Rootstocks
}

\author{
Laureano Alvarado, Sebastián Saa, Italo F. Cuneo, Romina Pedreschi, Javiera Morales, Alejandra Larach, Wilson Barros, \\ Jeannette Guajardo, and Ximena Besoain ${ }^{\dagger}$ \\ Escuela de Agronomía, Pontificia Universidad Católica de Valparaíso, Quillota, Chile
}

Abstract

\begin{abstract}
Clonal rootstocks are one alternative used by the walnut industry to control damage caused by Phytophthora species, traditionally using plants grafted on susceptible Juglans regia rootstock. Vlach, VX211, and RX1 are clonal rootstocks with a degree of resistance to Phytophthora species. The resistance to pathogens in these rootstocks depends on the resistance mechanisms activated by the presence of the pathogen and subsequent development of responses in the host. In this work, we analyzed how plants of J. regia, Vlach, VX211, and RX1 responded to inoculation with Phytophthora cinnamomi or Phytophthora citrophthora isolates obtained from diseased English walnut plants from Chilean orchards. After inoculation, plants of Vlach, VX211, and RX1 showed canopy and root damage indexes that did not differ from noninoculated control plants. In contrast, plants of $J$. regia, which is susceptible to $P$. cinnamomi and P. citrophthora, died after inoculation. Vlach, VX211,
\end{abstract}

and RX1 plants inoculated with $P$. cinnamomi or $P$. citrophthora showed greater root weight and volume and greater root growth rates than their respective controls. These results suggest that short-term carbohydrate dynamics may be related to the defense mechanisms of plants; they are immediately activated after inoculation through the production of phenolic compounds, which support the further growth and development of roots in walnut clonal rootstocks. To our knowledge, this is the first study that comprehensively characterizes vegetative and radicular growth and the dynamics of sugars and phenols in response to infection with $P$. cinnamomi or $P$. citrophthora in walnut rootstocks.

Keywords: clonal walnut rootstocks, carbohydrate dynamics, Juglans regia, phenolic compounds, Phytophthora cinnamomi, Phytophthora citrophthora, root-canopy growth
Different Phytophthora species associated with root and crown rot disease have been identified in English walnut (Juglans regia L.) (Matheron and Mircetich 1985a; Mircetich et al. 1998). The most characteristic symptoms of this disease are the presence of dark brown cankers and the release of black ooze at the crown, leaf discoloration, general decay, and plant death (Belisario et al. 2016; Browne et al. 2012; Ginetti et al. 2014; Guajardo et al. 2017; Kurbetli 2013). Among the most relevant Phytophthora species causing disease in English walnut are Phytophthora cinnamomi Rands and Phytophthora citricola Sawada (Belisario et al. 2016; Derviş 2016; Matheron and Mircetich 1985a, b, c; Mircetich and Matheron 1983; Mircetich et al. 1998). P. cinnamomi and $P$. citrophthora have been reported as the most damaging and prevalent species in Chile (Guajardo et al. $2017,2019)$. It has been determined that $93.3 \%$ of the English walnut orchards analyzed in Chile were affected by crown and root rot, with an average incidence of $15.7 \%$ (Guajardo et al. 2017).

Baumgartner et al. (2013), Browne et al. (2009, 2011), Buzo et al. (2009), Matheron and Mircetich (1985a, c), and Mircetich et al. (1998) studied different hybrid and nonhybrid seed rootstocks selected to survive the attack of Phytophthora and other soil pathogens (e.g., Armillaria spp. and nematodes). However, these rootstocks have not completely solved the problems caused by Phytophthora species (Browne et al. 2015). Seed rootstocks represent $80 \%$ of the

${ }^{\dagger}$ Corresponding author: X. Besoain; ximena.besoain@pucv.cl

Funding: This work was supported by Fundación para la Innovación Agraria (FIA) grant PYT-2016-0065.

*The $\boldsymbol{e}$-Xtra logo stands for "electronic extra" and indicates that two supplementary figures and one supplementary table are published online.

The author(s) declare no conflict of interest.

Accepted for publication 9 September 2019.

C 2020 The American Phytopathological Society rootstocks used in California, where the hybrid Paradox is the most widely planted (Browne et al. 2015). In Chile, $95 \%$ of planted rootstocks correspond to J. regia seedlings (Oficina de Estudios y Políticas Agrarias 2015), which are sensitive to root and crown rot. With breakthroughs in micropropagation and walnut tree cloning achieved at the University of California in Davis, California, researchers were able to select hybrid clonal rootstocks that provided consistent resistance to several soil pathogens, such as $P$. cinnamomi or P. citricola (Baumgartner et al. 2013; Browne et al. 2013, 2015; Buzo et al. 2009; McGranahan et al. 2005). Previous work suggested that clones from parentages Juglans hindsii $\times J$. regia and $(J$. hindsii $\times$ $J$. regia) $\times J$. regia are less susceptible to $P$. cinnamomi and $P$. citricola than other clones from other parentages (Browne et al. 2015). Similarly, although Juglans microcarpa and J. regia were reported to be susceptible to $P$. citricola, on comparison, the hybrids from $J$. microcarpa $\times J$. regia parentage expressed greater resistance to P. cinnamomi and P. citricola (Browne et al. 2015). Among these rootstocks, clones of $J$. microcarpa $\times J$. regia (e.g., RX1) and combinations of $J$. hindsii $\times J$. regia (e.g., Vlach and VX211) are cataloged as tolerant and/or resistant to $P$. cinnamomi or $P$. citricola (Browne et al. 2015; Kluepfel et al. 2015). Compared with different susceptible rootstocks, such as $J$. hindsii and combinations of Juglans californica $\times$ $J$. regia, the diverse selection of hybrid Paradox rootstock had up to $70 \%$ of crown and root rot incidence. In contrast, the best selection of clonal rootstocks (i.e., Vlach, VX211, and RX1) showed an average of 10 to $20 \%$ of crown and root rot incidence (Browne et al. 2015).

Low damage incidence is related to the specific growth and developmental responses produced by the pathogen-host interaction that induce resistance mechanisms related to plant defense. These responses reduce or prevent the damage caused by the growth of pathogenic hyphae in the roots (Agrios 1986; Cruz et al. 2006). The resistance mechanisms can be related to the formation of compounds that provide mechanical or chemical resistance to Phytophthora spp., such as lignin compounds and phenols/phytoalexins (Cruz et al. 2006; Del Río et al. 2001; Takemoto and Mizuno 2016; Treutter 2005; Vleeshouwers et al. 2000). For example, grape and avocado plants infected with $P$. cinnamomi present formation of tyloses as 
well as production of phenolic compounds that maintain stability and defend against the pathogen (Andrade-Hoyos et al. 2015; Del Río et al. 2001). As a result of these defense mechanisms, modifications related to canopy and root growth occur, allowing in vivo evaluation of the evolution of the damage. In avocado trees, a previous study highlighted the importance of root growth-stimulated microorganisms (rhizobacteria) playing a bioantagonistic role, allowing the plant to survive root rot caused by $P$. cinnamomi (Mendez-Bravo et al. 2018). In walnuts, Buzo et al. (2009) and McKenry and Buzo (2008) argued that survival of soil pathogens, specifically nematodes, is enabled by higher root growth and vigor in VX211 plants.

Pathogenicity trials with walnut rootstocks evaluated the damage caused by inoculation with $P$. cinnamomi or $P$. citricola by measuring the percentage of root and crown rot (Browne et al. 2011, 2015). Nevertheless, the specific interactions between Phytophthora species and walnut rootstocks and the consequences in terms of canopy and root growth, phenolic compound production (PCP), and carbohydrate dynamics associated with resistance to this pathogen remain largely unknown. In this work, we aimed to establish the importance of defensive responses in seedlings of $J$. regia and clonal walnut rootstock plants (Vlach, VX211, and RX1) after inoculation with $P$. cinnamomi and $P$. citrophthora isolates obtained from Chile. Evaluation was done at different stages after inoculation, measuring redistribution of soluble sugars and starch, PCP, canopy and root growth, and damage variables.

\section{Materials and Methods}

Plant material and trial conditions. Seedling plants of J. regia and clonal plants of Vlach, VX211, and RX1 rootstocks were used. Rootstocks plants were propagated from seeds or in vitro and provided by The Consortium of Nurseries of Chile. Plants were placed in 0.5 -liter pots filled with $70 \%$ white peat and $30 \%$ coconut fiber, and they were maintained under greenhouse conditions. Plants used in each trial were selected according to their vigor homogeneity (i.e., plant height and stem diameter). Different containers were used for each trial: 10-liter pots for the pathogenicity and growth trial, 5-liter containers for root growth in the rhizotron trial (i.e., short-term response trials), and 7-liter pots in the trial testing carbohydrates and phenolic compound dynamics (i.e., immediate response trials). Pots were filled with $40 \%$ sand, $40 \%$ white peat, and $20 \%$ coconut fiber. Rhizotrons were filled with $20 \%$ sand, $40 \%$ white peat, and $40 \%$ coconut fiber. Different pots were used for each trial because of the methodological requirements of each: 10-liter pots were used to perform evaluations $>30$ days after inoculation (DAI), rhizotrons require glass walls and less sand for proper root visibility in contrast to coconut fiber, and 7-liter containers were used for immediate evaluations after inoculation. All materials and substrates were previously disinfected. Plants were maintained in a greenhouse under controlled temperature $\left(25 \pm 1^{\circ} \mathrm{C}\right)$ for 3 months. Trials started with 12 - to 15-month-old plants (postpropagation age). All trials were done simultaneously at the Escuela de Agronomía, Pontificia Universidad Católica de Valparaíso (PUCV) in Quillota, Chile.

Inoculation with $\boldsymbol{P}$. cinnamomi or $\boldsymbol{P}$. citrophthora. The isolates were obtained from the Phytopathogen Bank of the Phytopathology Laboratory, PUCV. The P. cinnamomi isolate (1955) matches the GenBank codes for ITS MH236245, $\beta$-tubulin MH427884, and COI MH448656. The P. citrophthora isolate (1994) matches the codes MH368449 for ITS and MH427892 for $\beta$-tubulin. Isolates 1955 (P. cinnamomi) and 1994 (P. citrophthora) were selected, because they were previously tested and highlighted because of their aggressiveness (Guajardo et al. 2019). In addition, previous trials with isolate 1956 of $P$. cinnamomi (ITS MH236246 and MH427885 for

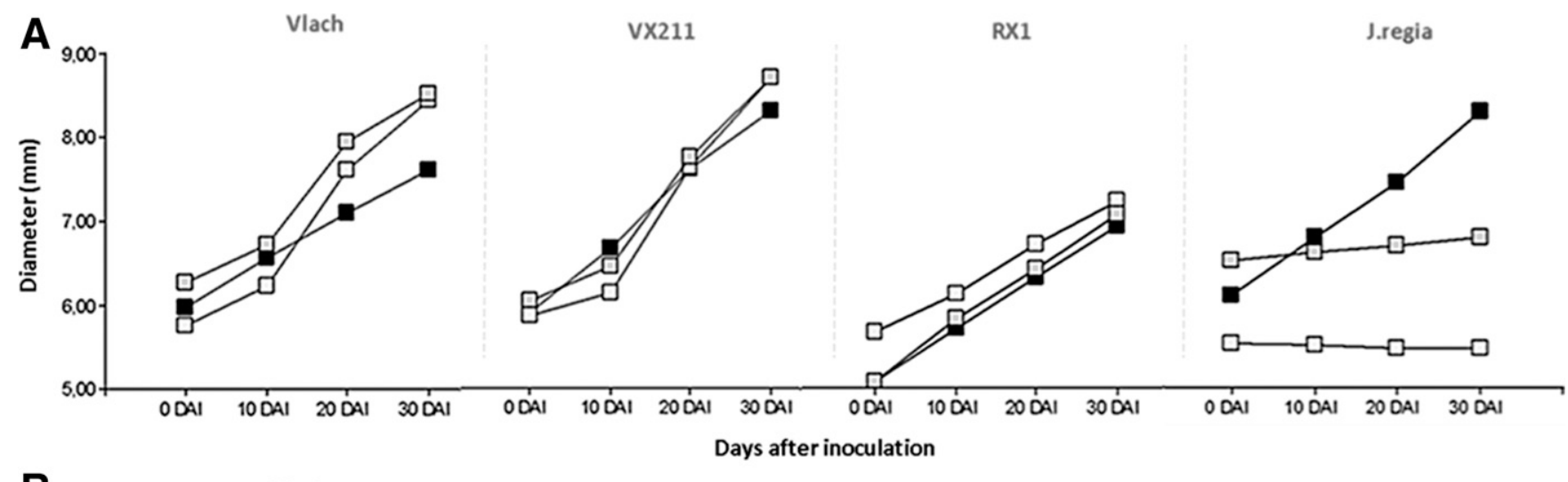

B

VX211 RX1 J.regia
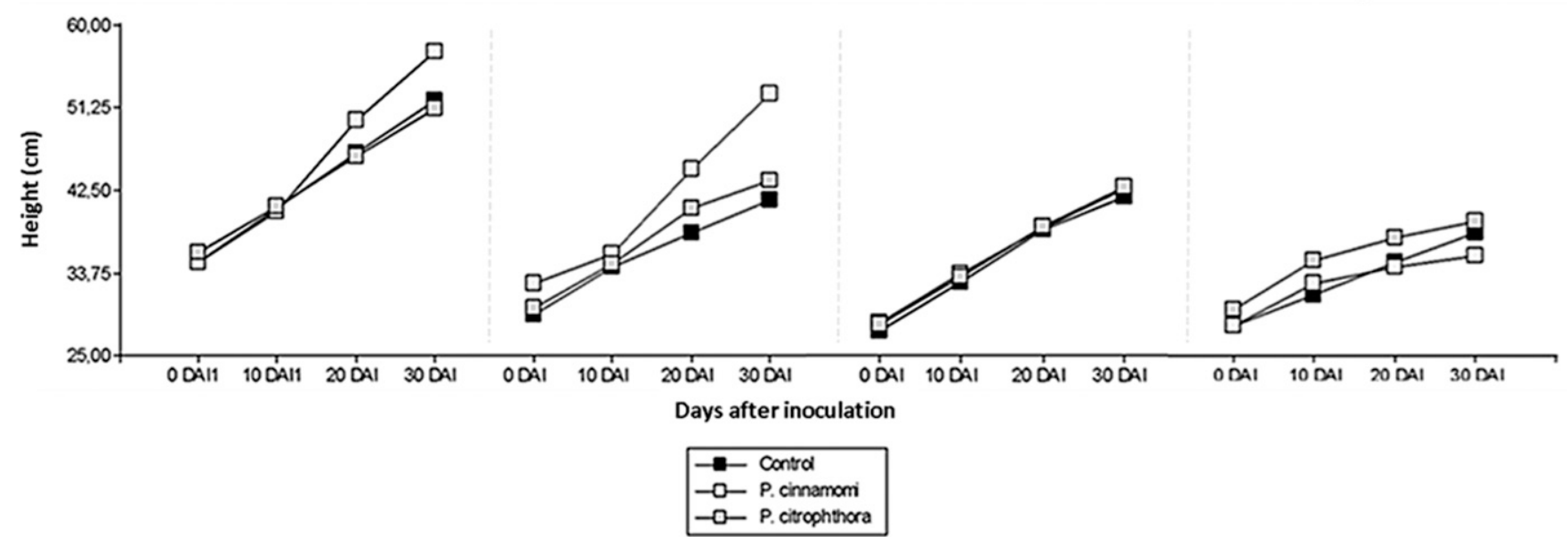

Fig. 1. Evolution of A, diameter (millimeters) and $\mathbf{B}$, height (centimeters) according to rootstock and differences ( $\Delta$ diameter or height) observed at intervals of 10 days after inoculation (DAl). The graph corresponds to Table 1 results. Observe the differences in trend between rootstocks and inoculation treatment, highlighting the tendency to decrease the differences on stem diameter and height of the rootstock plant Juglans regia. P. cinnamomi, Phytophthora cinnamomi; P. citrophthora, Phytophthora citrophthora. 
$\beta$-tubulin) that compared the susceptibility of J. regia and Vlach rootstocks were conducted in this research (Supplementary Fig. S1). In both cases, the same results were obtained in terms of pathogenicity and immediate and short-term responses. For the inoculum formulation and inoculation, methodologies described by Erwin and Ribeiro (1996) and Messenger et al. (2000) and modified by Guajardo et al. (2019) and Larach et al. (2009) were used. Mycelium discs were obtained from the tip of an actively growing colony of $P$. cinnamomi or $P$. citrophthora, and they were cultured in 1-liter containers with carrot juice at $25^{\circ} \mathrm{C}$ for 3 days. After this period, the developed mycelia were washed in saline solution for $3 \mathrm{~min}$, and then, sterile distilled water was added and maintained for 2 more days. The suspension of homogenized inoculum was applied by pouring a volume of $30 \mathrm{ml}$ of suspension per liter of substrate onto the substrate around each plant to achieve a uniform distribution of inoculum on the substrate and favoring the conditions for Phytophthora infection. The mycelium and sporangia suspension was applied in a concentration of $1.0 \times 10^{4}$ zoospores per milliliter ${ }^{-1}$, measured with a hemocytometer, and observed with an optical microscope after being fixed with a drop of cotton blue stain (Merck

Pathogenicity and growth trial. Stem diameter and plant height evaluation. Stem diameter (millimeters) was measured at $4 \mathrm{~cm}$ from the crown, and plant height was measured up to the tip of the stem apex (centimeters). These measurements were taken before inoculation (0 DAI) and every 10 DAI (10, 20, and 30 DAI).

Canker length evaluation and foliage and root damage indexes. Canker length (centimeters) was measured 30 DAI. Foliage damage and root damage were measured by removing each plant from its pot to verify the total damage. Roots were washed with a $1 \%$ isopropyl alcohol solution (Merck) while trying to preserve the root volume. Both of the indexes, damage index for foliage (DIF) and damage index for roots (DIR), were evaluated based on the modified damage scale of Vettraino et al. (2003). The DIF damage levels used were 0 , plant with a healthy foliar aspect; 1,1 to $25 \%$ foliar damage (necrosis or chlorosis); 2,26 to $50 \%$ foliar damage; 3,51 to $75 \%$ foliar damage; and 4, 76 to $100 \%$ foliar damage. For DIR, the damage levels used were 0 , plant without root rot; 1,1 to $25 \%$ rot (necrosis) of the total root volume; 2,26 to $50 \%$ root rot; 3,51 to $75 \%$ root rot; and 4,76 to $100 \%$ root rot. Percentages of root and foliage damage were also recorded to be correlated with other variables.

For the foliage, stem, root weight, and root volume evaluations, the fresh weights (grams) were measured for leaves, roots, and stems that had been separated and weighed on a digital scale. Dry weight (grams) was measured after a drying step in a forced air circulation oven (314 M230Z14; Quimis) at $65^{\circ} \mathrm{C}$. Root volume measurements (centimeters ${ }^{3}$ ) were taken by displacing a defined water volume in 2-liter graduated beakers. This measurement was done before drying the roots in the oven for measuring the dry weight.

Root growth on rhizotron trial. Growth rate and total growth of roots were evaluated using a rhizotron. Mica pieces superimposed on the glass wall of the rhizotrons were marked with permanent markers in between measurements every 2 to 3 days according to the growth of at least 10 independent subsamples (roots). The glass wall was covered between measurements to provide darkness. The rhizotron was positioned at a $45^{\circ}$ angle to the glass wall facing downward owing to the roots' negative geotropism, favoring root growth near the walls. The root growth measurements were made throughout the trial with ImageJ software. On data processing, data were expressed as the growth rate (millimeters per day) from 20 days before inoculation (DBI) up to 30 DAI. Total growth (millimeters) was expressed in root growth from 10 to $0 \mathrm{DBI}, 0$ to $10 \mathrm{DAI}, 10$ to $20 \mathrm{DAI}$, and 20 to 30 DAI. This trial used only isolates of $P$. cinnamomi owing to the relevance of this species in Chile.

Carbohydrate dynamics trial: Soluble sugar and starch content evaluation. Roots were extracted at 0 and $240 \mathrm{~h}$ after inoculation (HAI) with P. cinnamomi, washed with distilled water, and dried with absorbent sterile paper. Afterward, according to the methodology of Laskowski (2010), each root was dipped in liquid nitrogen and processed in an analytical mill (A11 Basic; IKA). After the samples were processed, they were preserved at $-20^{\circ} \mathrm{C}$ to be freeze dried (BK-FD10; BioBase) and finally, stored at $-80^{\circ} \mathrm{C}$ (F702; ThermoScientific) until analysis. Then, $0.1 \mathrm{~g}$ of each sample was weighed in triplicate, and $4 \mathrm{ml}$ of $50 \mathrm{mM}$ sodium acetate buffer ( $\mathrm{pH}$ 5.0) was added as the extraction solution. This solution was incubated while being shaken for $30 \mathrm{~min}$. Afterward, samples were centrifuged (C2500-230V; Labnet) at $3,500 \times g$ for $30 \mathrm{~min}$. The procedures and measurements of total soluble sugars contents (milligrams. gram $^{-1}$ ) were made by applying the phenol-sulfuric method of DuBois et al. (1956). Thus, $2 \mathrm{ml}$ of supernatant from each sample was mixed in triplicate with $2 \mathrm{ml}$ of $5 \%$ phenol in test tubes and placed in a rack submerged in cold water. Then, $5 \mathrm{ml}$ of sulfuric acid $\left(\mathrm{H}_{2} \mathrm{SO}_{4}\right)$ was added to the tubes, which were left to stand for $15 \mathrm{~min}$; then, it analyzed with a spectrophotometer at a wavelength of $490 \mathrm{~nm}$, and the starch concentration was measured based on the methodology of Sperling et al. (2017) and modified by Fernandez et al. (2018) with a glucose standard. For this experiment, $40 \mathrm{mg}$ of milled roots were mixed with $1 \mathrm{ml}$ of ultrapure water, and the mixture was incubated at $70^{\circ} \mathrm{C}$ for $15 \mathrm{~min}$ in a temperature-regulating

Table 1. Evolution of the differences of diameter of the stem (millimeters) and height of the plant (centimeters) according to intervals of 10 days for each rootstock and inoculating treatment ${ }^{\mathrm{x}}$

\begin{tabular}{|c|c|c|c|c|c|c|}
\hline Rootstock and inoculum & $\Delta \mathbf{D}_{\mathbf{1}}{ }^{\mathbf{y}}$ & $\Delta \mathbf{D}_{2}{ }^{\mathbf{y}}$ & $\Delta \mathbf{D}_{3}{ }^{\mathbf{y}}$ & $\Delta \mathbf{H}_{\mathbf{1}} \mathbf{z}$ & $\Delta \mathbf{H}_{2}^{\mathbf{z}}$ & $\Delta \mathbf{H}_{3} \mathbf{z}$ \\
\hline \multicolumn{7}{|l|}{ Vlach } \\
\hline Control & $0.59 \mathrm{abcd}$ & $0.54 \mathrm{~cd}$ & $0.51 \mathrm{bcd}$ & $5.66 \mathrm{a}$ & $5.90 \mathrm{~b}$ & $5.52 \mathrm{~b}$ \\
\hline Phytophthora cinnamomi & $0.47 \mathrm{bcd}$ & $1.39 \mathrm{ab}$ & $0.82 \mathrm{ab}$ & $5.36 \mathrm{ab}$ & $9.14 \mathrm{a}$ & $7.36 \mathrm{a}$ \\
\hline Phytophthora citrophthora & $0.46 \mathrm{bcd}$ & $1.23 \mathrm{ab}$ & $0.57 \mathrm{bc}$ & $4.78 \mathrm{abc}$ & $5.46 \mathrm{~b}$ & $4.98 \mathrm{bc}$ \\
\hline \multicolumn{7}{|l|}{ VX211 } \\
\hline Control & $0.77 \mathrm{ab}$ & $0.96 \mathrm{bc}$ & 0.18 cde & $5.02 a b c$ & $3.74 \mathrm{bc}$ & $3.36 \mathrm{cde}$ \\
\hline Phytophthora cinnamomi & $0.29 \mathrm{def}$ & $1.49 \mathrm{a}$ & $1.08 \mathrm{a}$ & $2.98 \mathrm{c}$ & $9.60 \mathrm{a}$ & $7.86 \mathrm{a}$ \\
\hline Phytophthora citrophthora & 0.43 cde & $1.31 \mathrm{ab}$ & $0.95 \mathrm{ab}$ & $4.68 \mathrm{abc}$ & $5.92 \mathrm{~b}$ & $2.94 \mathrm{de}$ \\
\hline \multicolumn{7}{|l|}{$\mathrm{RX} 1$} \\
\hline Control & $0.69 \mathrm{abc}$ & $0.7 \mathrm{c}$ & $0.68 \mathrm{ab}$ & $5.18 \mathrm{ab}$ & $5.52 \mathrm{~b}$ & $3.50 \mathrm{~cd}$ \\
\hline Phytophthora cinnamomi & $0.50 \mathrm{abcd}$ & $0.67 \mathrm{c}$ & $0.57 \mathrm{bc}$ & $5.28 \mathrm{ab}$ & $4.84 \mathrm{bc}$ & $4.18 \mathrm{bcd}$ \\
\hline Phytophthora citrophthora & $0.83 \mathrm{a}$ & $0.66 \mathrm{c}$ & $0.74 \mathrm{ab}$ & $5.02 \mathrm{abc}$ & $5.48 \mathrm{~b}$ & $4.14 \mathrm{bcd}$ \\
\hline \multicolumn{7}{|l|}{ Juglans regia } \\
\hline Control & $0.68 \mathrm{abc}$ & $0.65 \mathrm{c}$ & $0.86 \mathrm{ab}$ & $3.22 \mathrm{bc}$ & $3.44 \mathrm{bc}$ & $3.12 \mathrm{de}$ \\
\hline Phytophthora cinnamomi & 0.02 ef & $-0.03 \mathrm{e}$ & $-0.02 \mathrm{e}$ & $4.48 \mathrm{abc}$ & $1.78 \mathrm{~d}$ & $1.14 \mathrm{f}$ \\
\hline Phytophthora citrophthora & $0.09 \mathrm{f}$ & $0.08 \mathrm{de}$ & $0.11 \mathrm{de}$ & $5.14 \mathrm{abc}$ & $2.42 \mathrm{~cd}$ & 1.84 ef \\
\hline
\end{tabular}

x Separation of means for each variable according to the Fisher least significant difference test $(P<0.05)$.

y Difference in diameter between 0 to 10 days from inoculation (DAI; $\left.\Delta \mathrm{D}_{1}\right), 10$ to $20 \mathrm{DAI}\left(\Delta \mathrm{D}_{2}\right)$, or 20 to $30 \mathrm{DAI}\left(\Delta \mathrm{D}_{3}\right)$.

${ }^{\mathrm{z}}$ Difference in height difference between 0 to $10 \mathrm{DAI}\left(\Delta \mathrm{H}_{1}\right), 10$ to $20 \mathrm{DAI}\left(\Delta \mathrm{H}_{2}\right)$, or 20 to $30 \mathrm{DAI}\left(\Delta \mathrm{H}_{3}\right)$. 
bath and then, centrifuged at $21,000 \times g$ for $10 \mathrm{~min}$. Two washing steps were then done to discard the supernatant. The final residue was incubated at $100^{\circ} \mathrm{C}$ for $10 \mathrm{~min}$ and then, mixed with $500 \mu \mathrm{l}$ of sodium acetate buffer, $100 \mu \mathrm{l}$ of $\alpha$-amylase ( 7 units. $\mathrm{ml}^{-1}$ ), and $100 \mu \mathrm{l}$ of amyloglucosidase (70 units. $\mathrm{ml}^{1}$ ). The mixture was incubated at $37^{\circ} \mathrm{C}$ for $4 \mathrm{~h}$ for the starch to be completely digested. It was then centrifuged for $5 \mathrm{~min}$ at $15,800 \times \mathrm{g}$. Then, $150 \mu \mathrm{l}$ of the supernatant was mixed with $150 \mu \mathrm{l}$ of 3,5-dinitrosalicylic acid. Finally, samples were incubated at $100^{\circ} \mathrm{C}$ for $15 \mathrm{~min}$, and then, an additional $700 \mu l$ of ultrapure water and $50 \mu l$ of Rochelle salts were added. Quantification was performed at $550 \mathrm{~nm}$ based on a calibration curve built with a glucose standard.

Phenolic compounds dynamics trial: Relative production of phenolic compounds. PCP was analyzed based on the methodology of Del Río et al. (2001) and Singleton and Rossi (1965). Roots at 0, 12,24 , and 48 HAI with $P$. cinnamomi were quickly and carefully removed. Roots were quickly washed with distilled water, dried with absorbent sterile paper, immersed in liquid nitrogen, and further processed in an analytical mill (A11 Basic; IKA) in a timeframe of 2 min per root. After they were milled, the samples were stored at $-20^{\circ} \mathrm{C}$, freeze dried (BK-FD10; BioBase), and further stored at $-80^{\circ} \mathrm{C}$ (F702; ThermoScientific) until analysis according to LindigCisneros et al. (2002). For the extraction, $3 \mathrm{~g}$ of sample was taken and subjected to serial solid-liquid extraction in 50-ml falcon tubes with $27 \mathrm{ml}$ of ethyl acetate and $3 \mathrm{ml}$ of $2 \mathrm{mM}$ sodium fluoride solution. The samples were stirred for one cycle of $24 \mathrm{~h}$ at room temperature. After that period, the samples were centrifuged at 9,500 $\times g$ (C2500-230V; Labnet) for $10 \mathrm{~min}$ at $10^{\circ} \mathrm{C}$, and then, the supernatants were recovered in 32-ml falcon tubes and centrifuged again under the previously described conditions. For quantification, following Tomás-Barberán and Espín (2001), $250 \mu \mathrm{l}$ of each supernatant was mixed with $15 \mathrm{ml}$ of distilled water and $1.25 \mathrm{ml}$ of $1 \mathrm{~N}$ FolinCiocalteau reagent (Merck) and allowed to stand at room temperature in the dark for $8 \mathrm{~min}$. Next, $3.75 \mathrm{ml}$ of $7.5 \%$ (wt/vol) sodium carbonate was added and completed with sterile distilled water to reach $25 \mathrm{ml}$. The complete mixture was stirred and allowed to stand for
$120 \mathrm{~min}$ in darkness at room temperature, and absorbance was measured at $760 \mathrm{~nm}$. Absolute quantifications (results not shown) were based on a calibration curve developed with a gallic acid standard (Merck). Results were expressed as relative PCP. The PCP corresponds to the relative production or abundance of phenolic compounds in any treatment compared with the control treatment $(1.0$ value).

Experimental design and statistical analysis. Short-term response trials. Pathogenicity and growth trials consisted of each rootstock (J. regia, Vlach, VX211, and $\mathrm{RX} 1)$ and an inoculation treatment (P. cinnamomi, P. citrophthora, or noninoculated control). A single plant was used as the experimental unit with five replicates per treatment ( 60 plants in total). The root growth in rhizotrons trial treatments consisted of each rootstock (J. regia, Vlach, VX211, and RX1) inoculated with $P$. cinnamomi. Time interval from inoculation was expressed using four levels: 10 to $0 \mathrm{DBI}$ and 0 to 10,10 to 20 , and 20 to $30 \mathrm{DAI}$. A single plant was used as the experimental unit with five replicates for each rootstock and 10 subsamples of the secondary roots (20 plants in total).

Immediate response trials. The carbohydrate dynamics trial used each rootstock (J. regia, Vlach, VX211, and RX1) inoculated with $P$. cinnamomi and the time of inoculation as factors; the latter had two levels that corresponded to 0 and $240 \mathrm{HAI}$. A single plant was used as the experimental unit with four replicates per treatment (32 plants in total). The phenolic compounds dynamics trial used each rootstock (J. regia, Vlach, VX211, and RX1) inoculated with $P$. cinnamomi and the time of inoculation as factors; the latter had four levels that corresponded to $0,12,24$, and 48 HAI. A single plant was used as the experimental unit with four replicates per treatment (64 plants in total).

All trials used a completely randomized design with a factorial structure, and they were repeated or previously tested to adjust the methodologies. Results of continuous variables (stem diameter [millimeters], plant height [centimeters], canker length [centimeters], dry and fresh weight [grams], root volume [centimeters ${ }^{3}$ ], total root growth [millimeters], carbohydrate content (milligrams.gram ${ }^{-1}$ ],

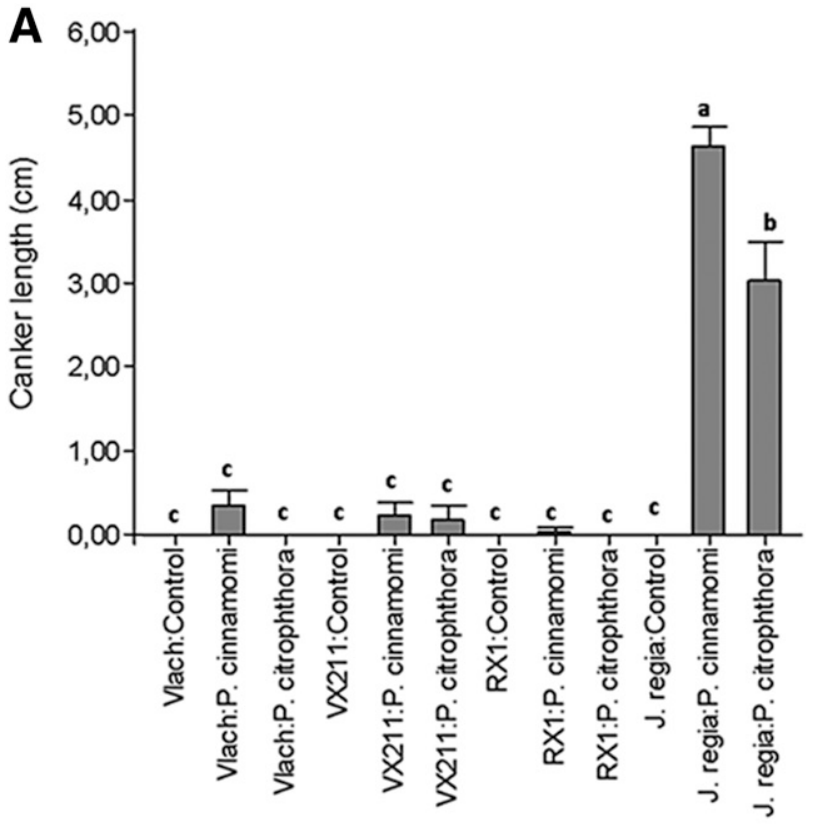

Rootstock- inoculum

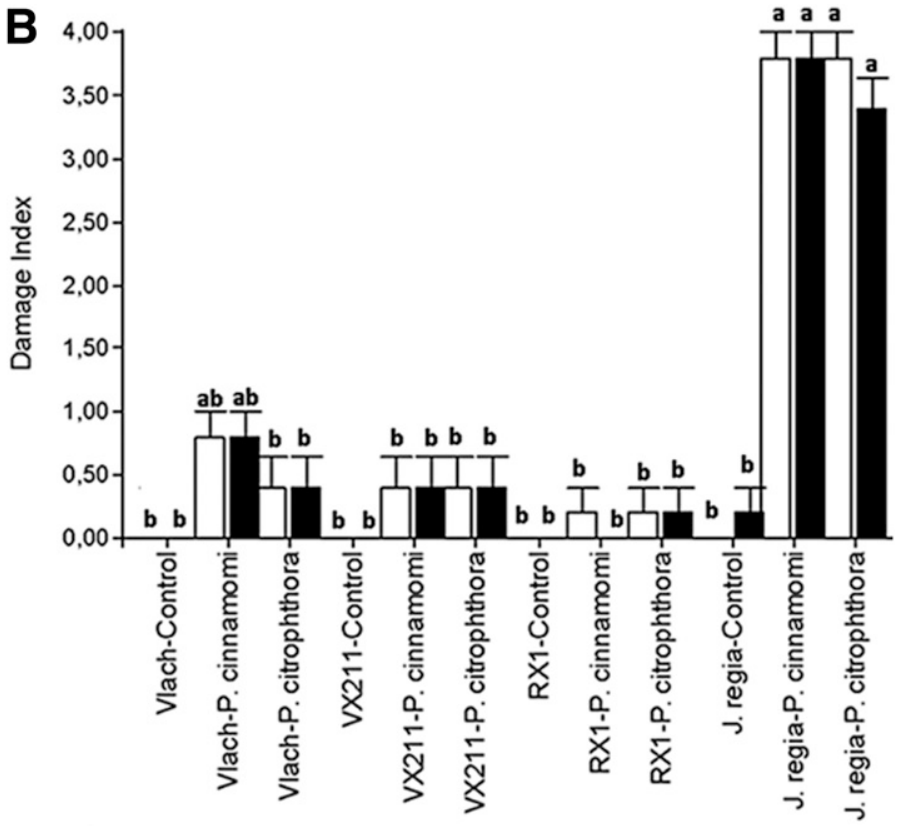

Rootstock - Inoculum

Fig. 2. A, Canker length (centimeters) and $\mathbf{B}$, damage index according to rootstock and Phytophthora inoculum. Separation of means for bars with a similar color according to $\mathbf{A}$ Tukey honestly significant difference test $(P<0.05)$ and $\mathbf{B}$, Kruskal-Wallis test $(P<0.05)$. DIF, damage index foliage; DIRs, damage index roots; J. regia, Juglans regia; $P$. cinnamomi, Phytophthora cinnamomi; P. citrophthora, Phytophthora citrophthora. 
and relative $\mathrm{PCP}$ ) were analyzed using an analysis of variance. The mean results were compared with Tukey HSD test or the Fisher LSD test $(P<0.05)$. For discrete variables (damage index), the nonparametric statistical analysis by Kruskal-Wallis $(P<0.05)$ was used. These analyses were conducted with InfoStat software (Di Rienzo et al. 2011). The variables obtained in the pathogenicity and growth tests were related to each other through the Pearson correlation index $(P<0.05)$. This index was used to measure the degree of relationship between the quantitative growth variables (weight and volume of different structures of each rootstock) with the quantitative variables of damage associated with the inoculation with
$P$. cinnamomi or $P$. citrophthora (percentage of damage and length of the canker) to establish how the growth of the plant is affected by the damage caused by the infection.

\section{Results}

Pathogenicity and growth trial. Vlach and VX211 plants inoculated with $P$. cinnamomi or $P$. citrophthora presented, starting at 10 DAI, a higher stem diameter growth than before 10 DAI. This increase was higher than that observed in the noninoculated controls for these rootstocks (Fig. 1A and Table 1). In contrast, inoculated J. regia plants showed a decrease in stem diameter growth, whereas
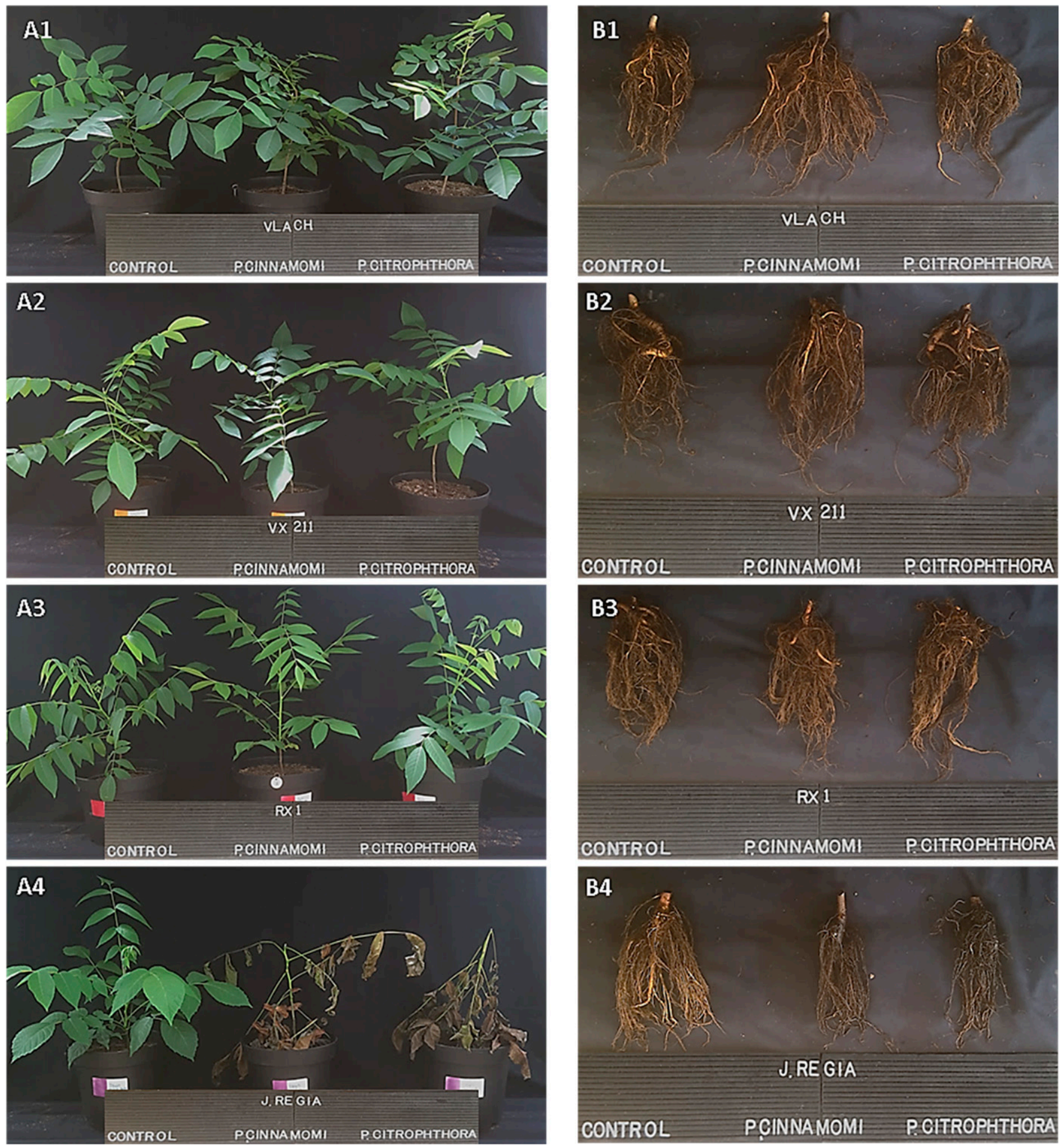

Fig. 3. A, Damage on leaves and B, damage on roots for all rootstocks. In all cases, the rootstocks are arranged from top to bottom as 1, Vlach, 2, VX211, 3, RX1, and 4, Juglans regia, and inoculum are arranged from left to right as control, Phytophthora cinnamomi, and Phytophthora citrophthora. 
noninoculated $J$. regia showed an increase in stem diameter (Fig. 1A and Table 1). VX211 and Vlach plants inoculated with P. cinnamomi, starting at $10 \mathrm{DAI}$, had a larger increase in plant height than before 10 DAI. RX1 and J. regia rootstocks had no height difference among the plants inoculated with $P$. cinnamomi, $P$. citrophthora, or noninoculated controls (Fig. 1B and Table 1).

Inoculated J. regia plants had significantly larger cankers, which were 4.62 and $3.02 \mathrm{~cm}$ for $P$. cinnamomi and $P$. citrophthora, respectively. Noninoculated $J$. regia plants and inoculated/noninoculated VX211, RX1, and Vlach plants showed very small to no cankers (Fig. 2A). Vlach, VX211, and RX1 presented foliage and root damage levels (DIF and DIR) similar to their corresponding controls (Fig. 2B). In contrast, J. regia plants inoculated with $P$. cinnamomi or $P$. citrophthora presented damage levels associated with $>90 \%$ necrosis and foliar chlorosis, severe root rot, and a high percentage of plant death (Fig. 3).

The evaluation of fresh and dry leaf weights had no significant differences among Vlach, VX211, and RX1 plants for both inoculated, and noninoculated plants. VX211 and Vlach plants inoculated with $P$. cinnamomi or $P$. citrophthora had higher fresh and dry weights of stem and roots than their respective noninoculated controls (Table 2). Only Vlach plants inoculated with P. cinnamomi showed a higher root volume than their respective control. J. regia plants inoculated with $P$. cinnamomi or $P$. citrophthora had lower root volumes and lower fresh and dry weights of leaves, stem, and roots than the other inoculated/noninoculated rootstock plants (Table 2).

Root growth in rhizotron trials. Root growth rate (millimeters. $\mathrm{day}^{-1}$ ) was similar among rootstocks before inoculation, whereas

Table 2. Fresh and dry weight (grams) of leaves, stem, and roots and root volume according to rootstock and inoculum ${ }^{\mathrm{y}}$

\begin{tabular}{|c|c|c|c|c|c|c|c|}
\hline Rootstock and inoculum & FWL $\mathbf{z}^{\mathbf{z}}$ & $\mathbf{D W L} \mathbf{L}^{\mathbf{z}}$ & $\mathbf{F W S}^{\mathbf{z}}$ & $\mathbf{D W S}^{\mathbf{z}}$ & $\mathbf{F W R} \mathbf{R}^{\mathbf{z}}$ & $\mathbf{D W R} \mathbf{R}^{\mathbf{z}}$ & $\mathbf{R} \mathbf{V}^{\mathbf{z}}$ \\
\hline \multicolumn{8}{|l|}{ Vlach } \\
\hline Control & $51.5 \mathrm{a}$ & $12.3 \mathrm{ab}$ & $12.7 \mathrm{e}$ & $5.3 \mathrm{e}$ & $62.2 \mathrm{abc}$ & $16.4 \mathrm{bc}$ & $87.0 \mathrm{bc}$ \\
\hline Phytophthora cinnamomi & $51.2 \mathrm{a}$ & $14.0 \mathrm{ab}$ & $20.7 \mathrm{~b}$ & $8.1 \mathrm{~b}$ & $79.3 \mathrm{a}$ & $24.8 \mathrm{a}$ & $114.0 \mathrm{a}$ \\
\hline P. citrophthora & $49.6 \mathrm{a}$ & $11.1 \mathrm{ab}$ & $16.0 \mathrm{~cd}$ & $6.7 \mathrm{~d}$ & $74.3 \mathrm{a}$ & $18.4 \mathrm{~b}$ & $105.0 \mathrm{abc}$ \\
\hline \multicolumn{8}{|l|}{ VX211 } \\
\hline Control & $47.9 \mathrm{a}$ & $11.2 \mathrm{ab}$ & $17.8 \mathrm{c}$ & $7.3 \mathrm{c}$ & $64.6 \mathrm{ab}$ & $17.6 \mathrm{~b}$ & $95.0 \mathrm{abc}$ \\
\hline P. cinnamomi & $49.6 \mathrm{a}$ & $13.3 \mathrm{ab}$ & 20.9 a & $8.1 \mathrm{a}$ & $77.6 \mathrm{a}$ & $24.9 \mathrm{a}$ & $115.0 \mathrm{a}$ \\
\hline P. citrophthora & $43.3 \mathrm{a}$ & $99.8 \mathrm{ab}$ & $20.6 \mathrm{a}$ & $8.0 \mathrm{a}$ & $75.4 \mathrm{a}$ & $24.3 \mathrm{a}$ & $110.0 \mathrm{ab}$ \\
\hline \multicolumn{8}{|l|}{$\mathrm{RX} 1$} \\
\hline Control & $42.3 \mathrm{a}$ & $13.9 \mathrm{a}$ & $13.3 \mathrm{e}$ & $5.4 \mathrm{e}$ & $50.8 \mathrm{bcd}$ & $12.8 \mathrm{~cd}$ & $85.0 \mathrm{bc}$ \\
\hline P. cinnamomi & $45.3 \mathrm{a}$ & $14.5 \mathrm{ab}$ & $14.5 \mathrm{de}$ & $5.3 \mathrm{e}$ & $52.6 \mathrm{bc}$ & $14.3 \mathrm{bcd}$ & $97.0 \mathrm{abc}$ \\
\hline P. citrophthora & $43.07 \mathrm{a}$ & $13.6 \mathrm{ab}$ & $13.1 \mathrm{e}$ & $5.3 \mathrm{e}$ & 44.1 cde & $10.7 \mathrm{de}$ & $81.0 \mathrm{c}$ \\
\hline \multicolumn{8}{|l|}{ Juglans regia } \\
\hline Control & $45.0 \mathrm{a}$ & $14.0 \mathrm{ab}$ & $9.5 \mathrm{f}$ & $3.3 \mathrm{f}$ & $53.7 \mathrm{bc}$ & $12.1 \mathrm{de}$ & $84.0 \mathrm{bc}$ \\
\hline P. cinnamomi & $21.0 \mathrm{~b}$ & $8.5 \mathrm{~b}$ & $6.7 \mathrm{~g}$ & $2.7 \mathrm{~g}$ & $29.9 \mathrm{e}$ & $6.3 \mathrm{e}$ & $38.0 \mathrm{~d}$ \\
\hline P. citrophthora & $23.3 \mathrm{~b}$ & $11.1 \mathrm{ab}$ & $7.0 \mathrm{~g}$ & $2.8 \mathrm{~g}$ & $32.8 \mathrm{de}$ & $8.2 \mathrm{ef}$ & $50.0 \mathrm{~d}$ \\
\hline
\end{tabular}

y Separation of means for each variable according to Tukey honestly significant difference test $(P<0.05)$.

z DWL, dry weight leaves (grams); DWR, dry weight root (grams); DWS, dry weight stem (grams); FWL, fresh weight leaves (grams); FWR, fresh weight root (grams); FWS, fresh weight stem (grams); RV, root volume (centimeter ${ }^{3}$ ).

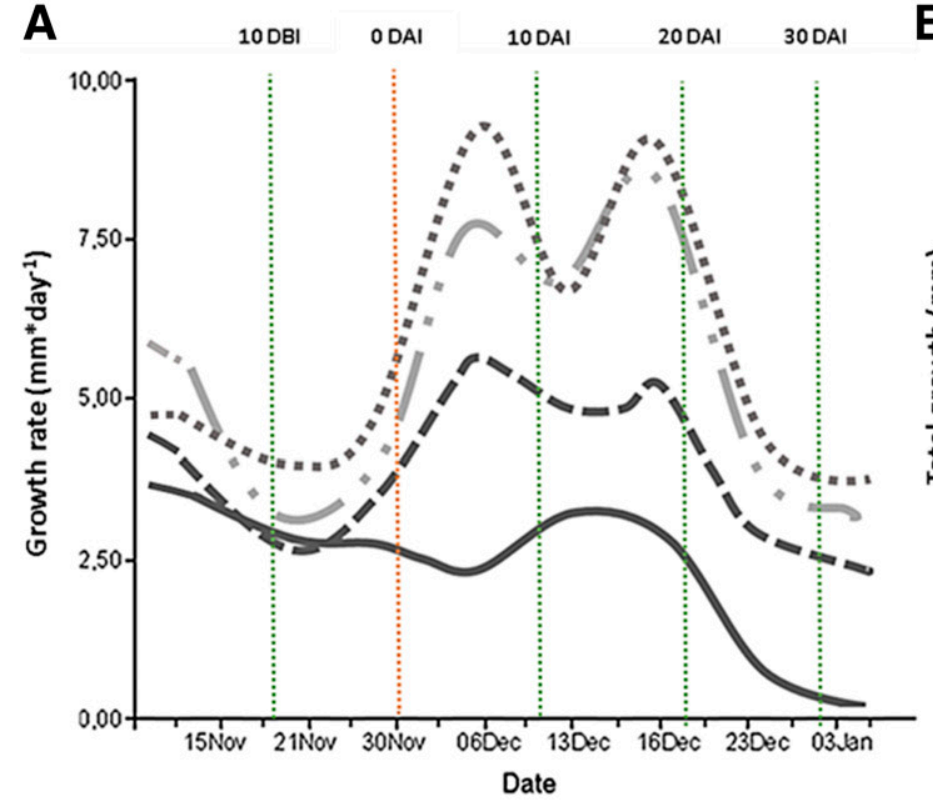

Jregia $\quad \cdots \cdot$ Vlach $-\cdots-V \times 211$ - - VX1

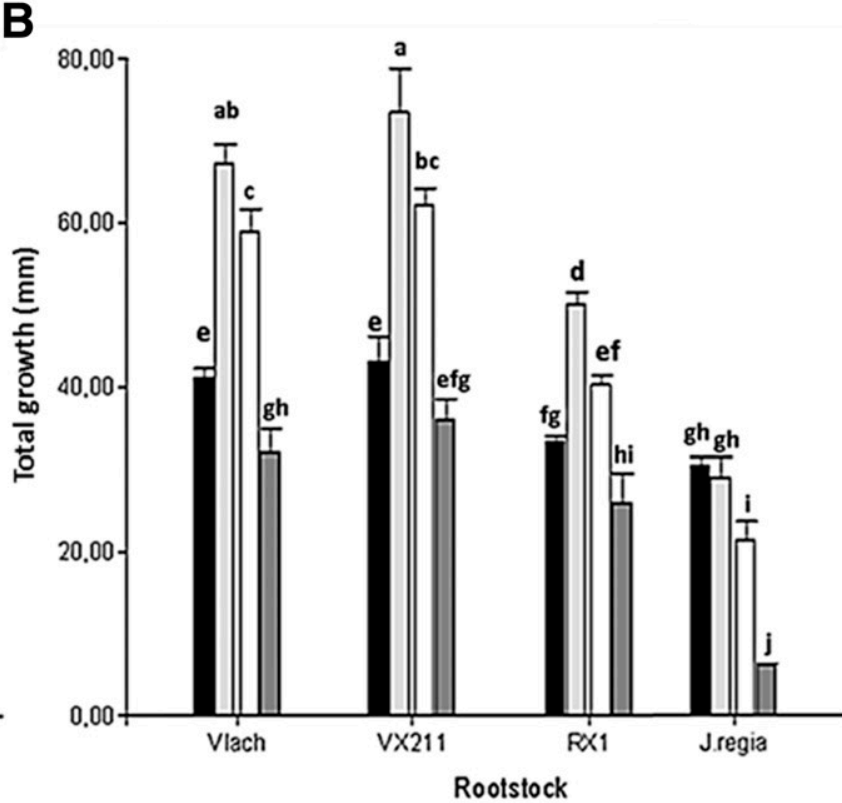

$10-009$

0-10DAI

10-20 DAl

20-30 DAl

Fig. 4. A, Growth rate (millimeters $\times$ diameter $^{-1}$ ) of roots before and after inoculation (30 November) and B, total growth (millimeters) by root in 10 -day intervals before inoculation (DBI) and after inoculation (DAI). Separation of means for all bars is according to Tukey honestly significant difference test $(P<0.05)$. J. regia, Juglans regia. 
clear differences were observed after inoculation (Fig. 4A). Vlach and VX211 plants had root growth rates that increased to $7.04 \mathrm{~mm} \cdot \mathrm{day}^{-1}$ (on average) up to the first $10 \mathrm{DAI}\left(3.6 \mathrm{~mm} \cdot \mathrm{day}^{-1}\right.$ ). After 20 DAI, the root growth rate of Vlach and VX211 plants gradually decreased until it was similar to that measured before inoculation (Fig. 4A). RX1 plants displayed a smaller increase in root growth rate compared with Vlach and VX211 plants, increasing from a root growth rate of $5.05 \mathrm{~mm} \cdot \mathrm{day}^{-1}$ on average for the first 10 DAI. Plants of $J$. regia maintained their root growth rate from before inoculation to up to $15 \mathrm{DAI}$ ( $3.5 \mathrm{~mm} \cdot \mathrm{day}^{-1}$ average). However, after this, a significant growth rate reduction was observed with values below $1 \mathrm{~mm} \cdot \mathrm{day}^{-1}$ (Fig. 4A), mainly associated with the damage caused by $P$. cinnamomi. Vlach and VX211 plants achieved a total growth of nearly $75 \mathrm{~mm}$ in the first 10 DAI. This value significantly exceeds the total growth value of $40 \mathrm{~mm}$ for the first $10 \mathrm{DBI}$ (Fig. 4B). Meanwhile, roots from J. regia plants grew at a decreasing rate, which was mainly associated with the root rot caused by the inoculation. Thus, $J$. regia plants had a total growth of $30.39 \mathrm{~mm}$ during $10 \mathrm{DBI}$, which decreased to a total of $6.22 \mathrm{~mm}$ between 20 and 30 DAI (Fig. 4B).

Carbohydrates and phenolic compounds dynamics trials. Total soluble sugars content for Vlach and VX211 plants increased after inoculation (Table 3). In contrast, RX1 and J. regia plants were not significantly different in sugar content. Only RX1 plants had a significant increase in starch (Table 3). Finally, a significant increase in the relative content of phenolic compounds was observed at $12 \mathrm{HAI}$ (Table 4). This relative content decreased after $24 \mathrm{HAI}$, reaching a PCP content similar to those observed before inoculation (0 HAI) for all rootstocks tested (Table 4).

\section{Discussion}

Studies evaluated the damage caused by $P$. cinnamomi and $P$. citricola in walnut rootstocks via the percentage of root rot and the presence of cankers (Browne et al. 2009, 2011, 2015). Also, previous studies inoculated juvenile clonal rootstock plants that were 6 to $8 \mathrm{~cm}$ in height with $P$. cinnamomi and $P$. citricola (Baumgartner et al. 2013; Browne et al. 2015), whereas our research used 12- to 15-month-old plants, which allowed us to better identify the immediate and short-term responses to the damage caused by $P$. cinnamomi and $P$. citrophthora. The results of the pathogenicity trial in this study were similar to those from previous studies from Browne et al. (2015), showing less damage in Vlach, VX211, and RX1 plants after inoculation with Phytophthora spp. in comparison with susceptible rootstocks. However, it should be noted that, in this study, clonal rootstocks, whether inoculated or not with $P$. cinnamomi or $P$. citrophthora, did not present significant damage as a result of the inoculation (Fig. 3). Furthermore, correlations between the studied variables suggest that canopy and root growth are adversely affected only when a plant has visible foliage and root damage (Supplementary Fig. S2 and Supplementary Table S1), which occurs

Table 3. Evolution of the content of soluble sugars or starch according to the rootstock before and after inoculation ${ }^{y}$

\begin{tabular}{|c|c|c|}
\hline Rootstock and HAI ${ }^{\mathbf{z}}$ & $\begin{array}{l}\text { Soluble sugars } \\
\quad\left(\mathrm{mg} / \mathrm{g}^{-1}\right)\end{array}$ & $\operatorname{Starch}\left(\mathrm{mg} / \mathrm{g}^{-1}\right)$ \\
\hline \multicolumn{3}{|l|}{ Vlach } \\
\hline 0 HAI & $44.90 \mathrm{c}$ & 21.45 cde \\
\hline $240 \mathrm{HAI}$ & $49.80 \mathrm{~b}$ & 17.76 def \\
\hline \multicolumn{3}{|l|}{ VX211 } \\
\hline 0 HAI & $49.79 \mathrm{~b}$ & $26.23 \mathrm{bcd}$ \\
\hline 240 HAI & $57.34 \mathrm{a}$ & $27.06 \mathrm{bc}$ \\
\hline \multicolumn{3}{|l|}{$\mathrm{RX} 1$} \\
\hline 0 HAI & $42.00 \mathrm{c}$ & $30.59 \mathrm{~b}$ \\
\hline 240 HAI & $46.10 \mathrm{bc}$ & $45.55 \mathrm{a}$ \\
\hline \multicolumn{3}{|l|}{ Juglans regia } \\
\hline $0 \mathrm{HAI}$ & $35.70 \mathrm{~d}$ & $14.63 \mathrm{ef}$ \\
\hline $240 \mathrm{HAI}$ & $36.26 \mathrm{~d}$ & $12.27 \mathrm{f}$ \\
\hline
\end{tabular}

${ }^{y}$ Separation of means according to the Tukey honestly significant difference test $(P<0.05)$.

${ }^{\mathrm{z}} \mathrm{HAI}$, hours after inoculation. because of the susceptibility of $J$. regia seed rootstocks to the Phytophthora species studied. Growth was not affected if there was no visible damage, which is consistent with results of VX211, Vlach, and RX1 capable of resisting $P$. cinnamomi and $P$. citrophthora damage (Supplementary Table S1).

The noninoculated $J$. regia plants had canopy and root growth similar to clonal rootstock plants. However, after they were inoculated, the plants were highly susceptible to $P$. cinnamomi and $P$. citrophthora, with maximum damage in the canopy and roots. These results are similar to those of Guajardo et al. (2019), and they are consistent with the results of this study showing smaller increases in stem diameter and plant height in J. regia plants compared with Vlach, VX211, and RX1 plants. In J. regia plants, inoculation causes a decrease in the leaf, stem, and root biomass, whereas the growth rate of the roots diminishes until growth is arrested when total rot occurs.

The responses of Vlach, VX211, and RX1 plants to P. cinnamomi are mainly positive. After they are inoculated, these plants present an increase in the content of phenolic compounds between 24 and 48 HAI, and they also present increases in the content of soluble sugar or starch during the first 10 DAI. These results suggest that Vlach, VX211, and RX1 have important mechanisms related to the formation of chemical compounds, like phenols, associated with resistance to Phytophthora spp., and it is energetically supported by the redistribution of sugars in the plant. Similarly, studies by Henriquez et al. (2012) and Kröner et al. (2012) suggested that the concentration of soluble phenolic compounds is important in the defense of plants, and results by Nagle et al. (2011) and Ockels et al. (2007) showed increases in the levels of phenolic compounds (gallic acid, catechin, tyrosol, a tyrosol derivative, ellagic acid, and four ellagic acid derivatives) extracted from the phloem of oak trees that had been artificially inoculated with Phytophthora ramorum. Other studies obtained similar results in eucalyptus (Cahill and McComb 1992) and avocado (Bekker et al. 2007) inoculated with P. cinnamomi, and in the study by Bengtsson et al. (2014), they found lesions similar to the hypersensitive response-like lesions surrounded by callose associated with an increase in soluble phenols concentrations in potato plants infected with Phytophthora infestans.

Couée et al. (2006) and Tauzin and Giardina (2014) confirmed that soluble sugars are the main form of assimilated carbon with an important function as signaling molecules and that they are involved in many metabolic processes in plants, being essential to plant defenses by activating the immune response against pathogens and stimulating plant growth and development. Defensive reactions against pathogens, such Phytophthora spp., do not involve negative metabolic costs in terms of growth (Bengtsson et al. 2014; Liljeroth et al. 2010). In studies such as that by Olivieri et al. (2009), there have even been increases in yield, where the yield of potato tubers in the short term increased after the mechanisms of resistance were induced under greenhouse conditions. Similar to Olivieri et al. (2009), in our study Vlach and VX211 plants showed increases in canopy and root growth, stem diameter, plant height, root volume, root weight, and

Table 4. Phenolic compound production (PCP) in roots of walnut rootstock before and after inoculation ${ }^{\mathrm{x}}$

\begin{tabular}{lcccc}
\hline & \multicolumn{4}{c}{ PCP } \\
\cline { 2 - 5 } Rootstock & 0 HAI & $\mathbf{1 2} \mathbf{H A I}^{\mathbf{y}}$ & $\mathbf{2 4} \mathbf{H A I} \mathbf{y}$ & $\mathbf{4 8 ~ H A I}$ \\
\hline Vlach & $9.80 \mathrm{~cd}$ & $18.82 \mathrm{gh}^{\mathrm{z}}$ & $10.52 \mathrm{cde}^{\mathrm{z}}$ & $9.24 \mathrm{~cd}$ \\
VX211 & $14.03 \mathrm{ef}$ & $15.70 \mathrm{fg}^{\mathrm{z}}$ & $11.58 \mathrm{de}^{\mathrm{z}}$ & $10.80 \mathrm{cde}$ \\
RX1 & $16.98 \mathrm{fg}$ & $25.16 \mathrm{i}^{\mathrm{z}}$ & $21.32 \mathrm{hi}^{\mathrm{z}}$ & $21.66 \mathrm{hi}$ \\
Juglans regia & $1.00 \mathrm{a}$ & $7.29 \mathrm{bc}^{\mathrm{z}}$ & $4.06 \mathrm{ab}^{\mathrm{z}}$ & $1.22 \mathrm{a}$ \\
\hline
\end{tabular}

x PCP is calculated as fold change or relative content of the abundance of phenolic compounds of each treatment with respect to the abundance of phenolic compounds of $J$. regia before inoculation (0 HAI). Separation of means between treatments according to Tukey honestly significant difference test $(P<0.05$; lowercase letters in the boxes).

y HAI, hours after inoculation.

${ }^{\mathrm{z}}$ Differences in the PCP value with respect to the control treatment (J. regia: 0 HAI) according to the Fisher least significant difference test $(P<0.05)$. 
stem weight in comparison with the corresponding noninoculated controls. Also, Vlach, VX211, and RX1 plants showed increases in root growth rates after inoculation. Therefore, responses to the changes of canopy and root growth and development in the short term were stimulated when the series of resistance reactions in Vlach, VX211, and RX1 was triggered in the presence of Phytophthora species immediately after inoculation.

In conclusion, our study allows us to determinate the effective resistance of walnut clonal rootstocks in the short term using variables relating to damage, growth, and development. Nevertheless, the resistance of walnut clonal rootstocks must be studied and complemented in the long term, evaluating the damage to roots and foliage under different conditions in the field (rhizotrons, damage scales, and others) both continuously and over time. In addition, the growth of the canopy and roots of clonal walnut rootstocks is an aspect that should be evaluated in long-term field tests, because the distribution of photosynthates and greater expressions of vigor brought on by the physiological responses that are provoked in defense of Phytophthora species can produce changes in production and productivity. Finally, it would be interesting to generate future genetic tests based on DNA sequences to segregate the resistance factors as suggested by Browne et al. (2015).

\section{Acknowledgments}

We thank the Asociación de Productores y Exportadores de Nueces de Chile, ChileNut, the Fundación para la Innovación Agraria, and the Consorcio de Viveros de Chile for their trust in the research team and their collaboration on the project "Integrated management for the control of Phytophthora in walnut." We recognize the collaboration of Natalia Riquelme, Aldo Salinas, Patricio Nuñez, and Ricardo Aravena, members of the Phytopathology Laboratory of Pontificia Universidad Católica de Valparaíso, who provided academic advice for the development of our research. Finally, we thank Mary Hopkins for reviewing technical English.

\section{Literature Cited}

Agrios, G. 1986. Pages 93-115 in: Fitopatología, 2nd Ed. Limusa, D. F., México.

Andrade-Hoyos, P., Molina, E., De León, C., Espíndola, M., Alvarado, D., and López- Jiménez, A. 2015. Defense mechanisms in avocado rootstocks to Phytophthora cinnamomi Rands. Spanish J. Rural Dev. 3:23-30.

Baumgartner, K., Fujiyoshi, P., Browne, G., Leslie, C., and Kluepfel, D. 2013. Evaluating Paradox walnut rootstocks for reistance to Armillaria root disease. HortScience 48:68-72.

Bekker, T., Aveling, T., Kaiser, C., Labuschagne, N., and Regnier, T. 2007. Accumulation of total phenolics due to silicon application in roots of avocado trees infected with Phytophthora cinnamomi. VI World Avocado Congress 2007. Viña Del Mar, Chile. 12-16 November 2007.

Belisario, A., Luongo, L., Vitale, S., Galli, M., and Haegi, A. 2016. Phytophthora gonapodyides causes decline and death of English (Persian) walnut (Juglans regia) in Italy. Plant Dis. 100:2537.

Bengtsson, T., Holefors, A., Witzell, J., Andreasso, E., and Liljerot, E. 2014. Activation of defence responses to Phytophthora infestans in potato by BABA. Plant Pathol. 63:193-202.

Browne, G., Bhat, R., Schmidt, L., Leslie, C., Michailides, T., Hackett, W., Robinson, R., Kluepfel, D., Aradhya, M., Beede, B., Buchner, R., Connell, J., Fichtner, E., Grant, J., and Hasey, J. 2012. Etiology and management of crown and root rots of walnut. Walnut Research Reports, California Walnut Board, University of California, Davis, CA.

Browne, G., Bhat, R., Schmidt, L., Leslie, C., Michailides, T., Hackett, W., Robinson, R., Kluepfel, D., Aradhya, M., Beede, B., Buchner, R., Connell, J., Fichtner, E., Grant, J., and Hasey, J. 2013. Etiology and management of crown and root rots of walnut: (Supplementary report for lethal paradox canker). Walnut Research Reports, California Walnut Board, University of California, Davis, CA.

Browne, G., Grant, J., Schmidt, L., Leslie, C., and McGranahan, G. 2011. Resistance to Phytophthora; and graft compatibility with Persian walnut among selections of Chinese wingnut. HortScience 46:371-376.

Browne, G., Leslie, C., Grant, J., Bhat, R., Schmidt, L., Hackett, W., Kluepfel, D., Robinson, R., and McGranahan, G. 2015. Resistance to species of Phytophthora identified among clones of Juglans microcarpa $x \mathrm{~J}$. regia. HortScience 50:1136-1142.

Browne, G., Schmidt, L., Bhat, R., Beede, B., Quesenberry, N., Leslie, C., Hackett, W., and McGranahan, G. 2009. Biology and management of phytophthora crown and root rot of walnut. Walnut Research Reports, California Walnut Board, University of California, Davis, CA.

Buzo, T., McKenna, J., Kaku, S., Anwar, S. A., and McKenry, M. V. 2009. VX211, a vigorous new walnut hybrid clone with nematode tolerance and a useful resistance mechanism. J. Nematol. 41:211-216.

Cahill, D., and McComb, J. A. 1992. A comparison of changes in phenylalanine ammonia-lyase activity, lignin and phenolic synthesis in the roots of Eucalyptus calophylla (field resistant) and E. marginata (susceptible) when infected with Phytophthora cinnamomi. Physiol. Mol. Plant Pathol. 40:315-332.

Couée, I., Sulmon, C., Gouesbet, G., and El Amrani, A. 2006. Involvement of soluble sugars in reactive oxygen species balance and responses to oxidative stress in plants. J. Exp. Bot. 57:449-459.

Cruz, B., Hernández, F., and Rivas, F. 2006. Mecanismos de resistencia de las plantas al ataque de patógenos y plagas. Temas de Ciencia y Tecnología 29: 45-54.

Del Río, J., González, A., Fuster, M., Botía, J., Gómez, P., Frías, V., and Ortuño, A. 2001. Tylose formation and changes in phenolic compounds of grape roots infected with Phaeomoniella chlamydospora and Phaeoacremonium species. Phytopathol. Mediterr. 40:394-399.

Derviş, S. 2016. First report of Phytophthora chlamydospora causing root rot on walnut (Juglans regia) trees in Turkey. Plant Dis. 100:2336.

Di Rienzo, J. A., Casanoves, F., Balzarini, M. G., Gonzalez, L., Tablada, M., and Robledo, C. W. 2011. Grupo InfoStat. FCA, Universidad Nacional de Córdoba, Córdoba, Argentina.

DuBois, M., Gilles, K. A., Hamilton, J. K., Rebers, P. A., and Smith, F. 1956. Colorimetric method for determination of sugars and related substances. Anal. Chem. 28:350-356.

Erwin, D. C., and Ribeiro, O. K. 1996. Phytophthora Diseases Worldwide. American Phytopathological Society Press, St. Paul, MN.

Fernandez, E., Baird, G., Farias, D., Oyanedel, E., Olaeta, J. A., Brown, P., Zwjeniecki, M., Tixier, A., and Saa, S. 2018. Fruit load in almond spurs define starch and total soluble carbohydrate concentration and therefore their survival and bloom probabilities in the next season. Sci. Hortic. (Amsterdam) 237:269-276.

Ginetti, B., Ragazzi, A., and Moricca, S. 2014. First report of Phytophthora taxon walnut in Lombardy, North Italy. Plant Dis. 98:424.

Guajardo, J., Saa, S., Camps, R., and Besoain, X. 2017. Outbreak of crown and root rot of walnut caused by Phytophthora cinnamomi in Chile. Plant Dis. 101:636.

Guajardo, J., Saa, S., Riquelme, N., Browne, G., Youlton, C., Castro, M., and Besoain, X. 2019. Characterization of oomycete species associated with root and crown rot of English walnut in Chile. Plant Dis. 103:691-696.

Henriquez, M. A., Adam, L. R., and Daayf, F. 2012. Alteration of secondary metabolites' profiles in potato leaves in response to weakly and highly aggressive isolates of Phytophthora infestans. Plant Physiol. Biochem. 57:8-14.

Kluepfel, D., Leslie, C., Aradhya, M., Browne, G., Hasey, J., Pope, K., McKenry, M., Westphal, A., Hackett, W., Bostock, R., Seybold, S., Dvorak, J., Luo, M., Coggeshall, M., Schlarbaum, S., Dandekar, A., Neale, D., Langley, C., Preece, J., and Baumgartner, K. 2015. Development of disease-resistant walnut rootstocks: Integration of conventional and genomic approaches. Walnut Research Reports, California Walnut Board, University of California, Davis, CA.

Kröner, A., Marnet, N., Andrivon, D., and Val, F. 2012. Nicotiflorin, rutin and chlorogenic acid: Phenylpropanoids involved differently in quantitative resistance of potato tubers to biotrophic and necrotrophic pathogens. Plant Physiol. Biochem. 57:23-31.

Kurbetli, I. 2013. Phytophthora cinnamomi associated with root and crown rot of walnut in Turkey. J. Phytopathol. 161:287-289.

Larach, A., Besoain, X., and Salgado, E. 2009. Crown and root rot of highbush blueberry caused by Phytophthora cinnamomi and P. citrophthora and cultivar susceptibility. Cienc. Investig. Agrar. 36:433-442.

Laskowski, L. E. 2010. Soluble carbohydrates content in pedicel and fruit during the initial growth of Citrus sinensis (L.) Osbeck. Interciencia 35:388-392.

Liljeroth, E., Bengtsson, T., Wiik, L., and Andreasson, E. 2010. Induced resistance in potato to Phytophthora infestans - effects of BABA in greenhouse and field tests with different potato varieties. Eur. J. Plant Pathol. 127:171-183.

Lindig-Cisneros, R., Dirzo, R., and Espinosa-Garcia, F. J. 2002. Effects of domestication and agronomic selection on phytoalexin antifungal defense in Phaseolus beans. Ecol. Res. 17:315-321.

Matheron, M., and Mircetich, S. 1985a. Pathogenicity and relative virulence of Phytophthora spp. from walnut and other plants to rootstocks of English walnut trees. Phytopathology 75:977-981.

Matheron, M., and Mircetich, S. 1985b. Relative resistance of different rootstocks of English walnut to six Phytophthora spp. that cause root and crown rot in orchard trees. Plant Dis. 69:1039-1041.

Matheron, M., and Mircetich, S. 1985c. Seasonal variation in susceptibility of Juglans hindsii and Paradox rootstocks of English walnut trees to Phytophthora citricola. Phytopathology 75:970-972.

McGranahan, G., Hackett, W., Lampinen, B., Leslie, C., Bujaznha, D., and Hirbod, S. 2005. Clonal propagation of walnut rootstock genotypes for genetic improvement. Walnut Research Reports, California Walnut Board, University of California, Davis, CA

McKenry, M., and Buzo, T. 2008. Methyl bromide alternatives, focus on rootstocks Walnut Research Reports, California Walnut Board, University of California, Davis, CA.

Mendez-Bravo, A., Cortázar-Murillo, E.M., Guevara-Avendaño, E., CeballosLuna, O., Rodríguez-Haas, B., Kiel-Martínez, A., Hernández-Cristóbal, O. Guerrero-Analco, J.A., and Reverchon, F. 2018. Plant growth-promoting rhizobacteria associated with avocado display antagonistic activity against Phytophthora cinnamomi through volatile emissions. PLoS One 20:1.

Messenger, B., Menge, J., and Pond, E. 2000. Effects of gypsum on zoospores and sporangia of Phytophthora cinnamomi in field soil. Plant Dis. 84:617-621. 
Mircetich, S., Browne, G., Matheron, M., and Teviotdale, B. 1998. Armillaria and Phytophthora root and crown rot diseases. Pages 221-232 in: Walnut Production Manual. D. E. Ramos, ed. University of California, Oakland, CA

Mircetich, S., and Matheron, M. 1983. Phytophthora root and crown rot of walnut trees. Phytopathology 73:1481-1488.

Nagle, A. M., Mcpherson, B. A., Wood, D. L., Garbelotto, M., and Bonello, P. 2011. Relationship between field resistance to Phytophthora ramorum and constitutive phenolic chemistry of coast live oak. For. Path. 41:464-469.

Ockels, F., Eyles, A., McPherson, B. A., Wood, D. L., and Bonello, P. 2007. Phenolic chemistry of coast live oak response to Phytophthora ramorum infection. J. Chem. Ecol. 33:1721-1732.

Oficina de Estudios y Políticas Agrarias. 2015. Actualización de la Comercialización de Plantas Frutales, Vides y Plantines de Hortalizas en Chile. Asociación Gremial de Viveros de Chile. Santiago, Chile. https:// www.odepa.gob.cl/wp-content/uploads/2015/12/estudioViveros2015.pdf

Olivieri, F. P., Lobato, M. C., and González Altamiranda, E. 2009. BABA effects on the behaviour of potato cultivars infected by Phytophthora infestans and Fusarium solani. Eur. J. Plant Pathol. 123:47-56.

Singleton, V. L., and Rossi, J. A. 1965. Colorimetry of total phenolics with phosphomolybdic phosphotungstic acid reagents. Am. J. Enol. Vitic. 16:144-158.
Sperling, O., Silva, L. C. R., Tixier, A., Théroux-Rancourt, G., and Zwjeniecki, M. A. 2017. Temperature gradients assist carbohydrate allocation within trees. Sci. Rep. 7:3265.

Takemoto, D., and Mizuno, Y. 2016. Belowground and aboveground strategies of plant resistance against Phytophthora species. Pages 151-169 in: Belowground Defence Strategies in Plants. Signaling and Communication in Plants. C. Vos and K. Kazan, eds. Springer International Publishing, Cham, Switzerland.

Tauzin, A. S., and Giardina, T. 2014. Sucrose and invertases, a part of the plant defense response to the biotic stresses. Front. Plant Science. 5:293.

Tomás-Barberán, F., and Espín, J. C. 2001. Phenolic compounds and related enzymes as determinants of quality in fruits and vegetables. J. Sci. Food Agric. 81:853-876.

Treutter, D. 2005. Significance of flavonoids in plant resistance and enhancement of their biosynthesis. Plant Biol. 7:581-591.

Vettraino, A., Belisario, A., Maccaroni, M., and Vannini, A. 2003. Evaluation of root damage to English walnut caused by five Phytophthora species. Plant Pathol. 52:491-495.

Vleeshouwers, V., Van Dooijeweert, W., Govers, F., Kamoun, S., and Colon, L. 2000. The hypersensitive response is associated with host and nonhost resistance to Phytophthora infestans. Planta 210:853-864. 